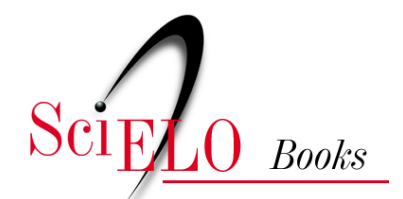

\title{
Capítulo 2 - Teoria e metodologia
}

\author{
Ivan Filipe de Almeida Lopes Fernandes
}

\section{SciELO Books / SciELO Livros / SciELO Libros}

FERNANDES, I.F.A.L. Teoria e metodologia. In: A democracia reduz a desigualdade econômica? Um estudo sobre as possibilidades de construção de uma sociedade mais igual por meio da democracia [online]. São Bernardo do Campo, SP: Editora UFABC, 2017, pp. 67-106. ISBN: 978-85-68576-79-3. https://doi.org/10.7476/9788568576793.0003.

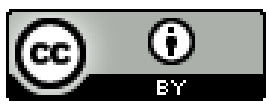

All the contents of this work, except where otherwise noted, is licensed under a Creative Commons Attribution 4.0 $\underline{\text { International license. }}$

Todo o conteúdo deste trabalho, exceto quando houver ressalva, é publicado sob a licença Creative Commons Atribição $\underline{4.0}$.

Todo el contenido de esta obra, excepto donde se indique lo contrario, está bajo licencia de la licencia $\underline{\text { Creative }}$ Commons Reconocimento 4.0. 


\section{Teoria e metodologia}

Após a breve discussão de alguns dos principais debates da economia política comparada sobre a desigualdade, neste capítulo apresentamos a contribuição teórica e a metodologia adequada para analisar as nossas hipóteses de pesquisa, expostas ao fim da seção 2.1.

Na primeira seção discutimos um tema pouco explorado no debate sobre a relação entre democracia e desigualdade: as condições necessárias para a competição política partidária ser realizada sobre o tema da desigualdade econômica. O ponto de partida teórico é o diagnóstico de que até agora a literatura sobre o tema parte de um pressuposto entre democracia e desigualdade que embora possa ser testado ainda não foi avaliado adequadamente: a homogeneidade dos efeitos da democracia ao longo da distribuição da desigualdade econômica. Isto é, se de fato o efeito da democracia sobre a desigualdade é o mesmo em sociedades iguais, em sociedades medianamente desiguais e em sociedades muito desiguais. A nossa abordagem teórica tentará responder esta questão fundamental para se compreender corretamente quais são os reais efeitos da democracia sobre a desigualdade econômica.

Na segunda seção apresentamos a metodologia da regressão quantílica que é a mais adequada para testar as hipóteses rivais da homogeneidade ou heterogeneidade dos efei- 
tos da democracia ao longo da distribuição da desigualdade econômica. Além disso, apresentamos também o ferramental metodológico de variável instrumental a partir do qual lidamos com o problema da causalidade inversa na relação entre democracia e desigualdade, de forma a verificarmos o que de fato é efeito da democracia sobre a desigualdade e não apenas reflexo dos próprios limites que o excesso de desigualdade econômica coloca na criação de sistemas políticos democráticos.

\subsection{Ativando a desigualdade como tema eleitoral}

A principal contribuição teórica da pesquisa é preencher a lacuna existente na literatura de economia política comparada a respeito da suposição, não testada, de que os efeitos da democracia sobre a desigualdade são homogêneos ao longo de diferentes contextos de desigualdades. Contudo, tal suposição não parece ser crível quando trazemos à baila o problema da multidimensionalidade da política democrática e ponderamos acerca de quais são as condições que estimulam o surgimento de uma demanda por redistribuição entre o eleitorado e, de outro lado, um interesse partidário em ofertar plataformas e políticas públicas que tratem diretamente deste problema socioeconômico. Posto isso, desenvolvemos a hipótese de que os efeitos da democracia sobre a desigualdade variam ao longo do próprio eixo da desigualdade econômica, sendo mais efetivos justamente nas sociedades mais desiguais, justamente aquelas nas quais existe maior possibilidade de surgir uma demanda e uma oferta por políticas redistributivas.

A construção desta proposta teórica parte de uma concepção minimalista e procedimental de democracia. Ao longo 
de toda pesquisa associamos o regime político democrático ao próprio processo de definição das lideranças e autoridades políticas via eleições. Desta maneira, a democracia é definida basicamente como um regime no qual as posições centrais de governo são preenchidas segundo os resultados de eleições competitivas, livres, certas e justas (PRZEWORSKI, 1991; VREELAND, 2003; SCHUMPETER, 2013)

Esta definição possui dois elementos fundantes: posições centrais de governo e competição política por meio de eleições. As posições centrais são os órgãos fundamentais da vida política de qualquer comunidade - os postos responsáveis pela criação e execução das leis. E para um regime ser democrático é necessário que o preenchimento das cadeiras nos corpos legislativo e executivo seja realizado por meio de um método eleitoral aberto e competitivo. Isto porque a existência de competição política indica a concorrência dos agentes políticos por esses postos, de forma que exista oposição ao atual governo cujas chances de vitória são reais ${ }^{26}$.

Diante desta definição de democracia como competição política, uma importante questão para a discussão da relação entre democracia e desigualdade foi, a nosso ver, deixada de lado pela literatura. Quais são as condições nas quais às lideranças partidárias de fato optam por destacar a questão da desigualdade econômica como argumento eleitoral em busca da

\footnotetext{
${ }^{26}$ As eleições necessitam de três condições fundamentais para cumprir com seu papel de mecanismo competitivo de definição das posições centrais do governo: i) incerteza ex ante de quem seja o vitorioso da competição eleitoral; ii) irreversibilidade ex post do resultado da competição eleitoral; e iii) repetitividade da competição eleitoral. Estas três características fundamentais determinam se as eleições são competitivas, livres, certas e justas. Uma justificação mais pormenorizada das razões teóricas e metodológicas da escolha da definição minimalista e procedimental de democracia é apresentada no Capítulo 3.
} 
obtenção de votos e apoio dos cidadãos e elaboram políticas públicas para reduzi-la? Propomos que essas condições se relacionam ao contexto socioeconômico que estimula (ou não) a oferta de plataformas políticas por parte das elites políticas e também cria ou arrefece a demanda por algum tipo de ação redistributiva no seio da cidadania, isto é por todos aqueles que participam da decisão sobre quem ocupa as posições centrais do governo ${ }^{27}$.

Do lado da oferta de plataformas políticas, é necessário incorporar a análise do cálculo do custo e benefício para os partidos das diferentes estratégias eleitorais disponíveis e quando se torna interessante para os competidores elaborar um discurso que tenha como centro o debate sobre a desigualdade econômica. Já do lado da cidadania, a massa de eleitores, é necessário observar quais são as condições que estimulam o surgimento de uma demanda política por redistribuição econômica na maior parte do eleitorado. Caso não se verifique simultaneamente uma demanda por redistribuição e um ganho político por parte dos partidos com a oferta de plataformas que atendam a esta demanda, não é esperado que a competição democrática tenha qualquer impacto sobre a distribuição de recursos econômicos.

Para tal, assumimos o pressuposto, a nosso ver não restritivo, de que em toda e qualquer comunidade política existe uma miríade de temas que podem ser politizados no debate entre os partidos e a cidadania. Assim, não é em qualquer momento ou contexto socioeconômico que a questão da desigualdade econômica será trazida à tona e recursos públicos e

27 Usaremos o termo cidadania, massa de eleitores e eleitorado como sinônimos que se referem ao conjunto de indivíduos aptos a exercer o direito político do voto. 
partidários serão despendidos com o intuito de minimizá-la. Outros problemas políticos latentes podem ser estimulados pelas lideranças políticas ou mesmo demandados pela própria cidadania. Exemplos são questões relacionadas à segurança nacional, os imperativos do desenvolvimento econômico, a defesa de princípios étnicos ou religiosos, separatismos ou mesmo a manutenção da unidade nacional, entre outros.

Piketty (2014) exemplifica esse fato ao lembrar que no período pós-Segunda Guerra Mundial, o debate político na Europa Ocidental era essencialmente voltado para o esforço de reconstrução nacional e não para os problemas da desigualdade econômica. Ademais, a própria questão da desigualdade econômica pode ser vista segundo outros prismas que não o problema da distribuição dos recursos entre os cidadãos. Gilens (2009) apresenta dados que relacionam o debate norte-americano sobre o estado de bem-estar social com a questão racial e econômica. A principal consequência desta associação entre pobreza e raça nos EUA foi reduzir a suscetibilidade política do argumento igualitário em uma sociedade na qual a raça é um componente importante do debate político ${ }^{28}$.

Desta forma, o pressuposto assumido pelo modelo redistributivo de Meltzer e Richard (1981), de que a política ocorre em uma única dimensão ideológica, pode ser uma hipótese demasiadamente forte ${ }^{29}$. Com efeito, o pressuposto da

\footnotetext{
${ }^{28}$ Poole e Rosenthal (2001) mostraram que os votos dos congressistas americanos desde 1789 são melhor explicados por duas dimensões: a questão tributária e a questão racial (escravidão antes da Guerra Civil e integração/direitos civis depois). Mais de $85 \%$ da variância dos votos no congresso estadunidense são explicados por essas duas dimensões.

29 No capítulo 1 apresentamos uma descrição mais pormenorizada sobre o modelo redistributivo de Meltzer e Richards e uma discussão crítica a respeito da validade de suas conclusões teóricas.
} 
unidimensionalidade é assumido como ferramenta heurística de simplificação da realidade política, visando facilitar a modelagem ou teorização informal sobre os principais efeitos e padrões da competição político-eleitoral. Contudo, ao assumir este pressuposto simplificador e deduzir implicações teóricas sobre os efeitos da competição política unidimensional nas eleições e no próprio desenrolar do sistema político analisado, é necessário o retorno à realidade sensorial para verificar se essas implicações teorizadas encontram respaldo empírico ${ }^{30}$.

O modelo do eleitor mediano apresentado por Hotelling (1929) e refinado por Downs (1957) é a ferramenta tradicional para o estudo do impacto da competição eleitoral nas sociedades democráticas e é o framework a partir do qual Meltzer e Richard elaboram o modelo redistributivo. O modelo do eleitor mediano assume uma competição política unidimensional e propõe a existência de um contínuo político, polarizado entre esquerda e direita, com um único equilíbrio: a apresentação pelos partidos de plataformas eleitorais de acordo com as orientações ideológicas do eleitor mediano (assumindo uma competição bipartidária).

Analisando a relação entre taxas de tributação e transferências de renda, Meltzer e Richard (1981) mostram que o ponto de equilíbrio do tamanho do governo em uma dada sociedade democrática seria definido pela distância da renda do eleitor mediano à renda média da população. Existindo,

\footnotetext{
30 Piketty (2014) aponta problemas semelhantes ao estudar a evolução da desigualdade econômica nas economias mais desenvolvidas. Para o autor a ciência econômica norte-americana (sobretudo) nas últimas décadas dedicou-se excessivamente ao desenvolvimento de modelos teóricos, deixando de lado a verificação empírica das implicações postuladas.
} 
portanto, uma tendência à redistribuição do topo para a base, uma vez que a curva de renda é usualmente desviada para a esquerda. Assim, em qualquer regra de votação na qual o eleitor mediano possui renda menor do que a renda média, existiriam incentivos para a redistribuição por meio da taxação dos mais ricos.

Ainda que não desejemos criticar o valor pedagógico da simplificação unidimensional, é preciso reconhecer que o tema que divide este espectro ideológico nem sempre é o mesmo, dependendo das circunstâncias e contextos nos quais a competição política ocorre. Em uma democracia, é razoável supor que a apresentação de quaisquer pautas políticas e mesmo a criação de políticas públicas com foco no horizonte eleitoral é feita em direção a temas que tenham um maior potencial de atração de votos. E o mesmo acontece com a desigualdade econômica.

O suposto de Meltzer e Richard (1981) de que a competição eleitoral sempre se dá sempre em torno das diferenças entre a renda média e a renda mediana de determinada comunidade política não reflete o fato que essa diferença só será politizável dadas certas circunstâncias socioeconômicas. Por exemplo, o próprio nível absoluto da distância entre a renda do eleitor mediano e a renda média e a não existência de debates e tensões que dividem a metade inferior da distribuição de renda em outras clivagens políticas além da questão redistributiva ${ }^{31}$.

31 A evolução da opinião pública polonesa sobre a desigualdade ao longo da
década de 1990 é clara sobre isso. No início do processo de democratização e
transformação econômica a desigualdade foi enxergada segundo um viés po-
sitivo: reflexo da ampliação das oportunidades com as reformas econômicas
pós-comunistas. Com o passar do tempo a tolerância à crescente desigualdade 
Ademais, os resultados dos testes empíricos sobre o modelo redistributivo foram insatisfatórios. As análises realizadas encontram um resultado absolutamente distinto daquele preconizado pelo modelo teórico. São justamente as sociedades mais igualitárias que tendem a produzir maior redistribuição do que as sociedades mais desiguais (BERAMENDI; ANDERSON, 2008) ainda que exista, como já referido no capítulo 1, um problema primordial na análise dos determinantes da redistribuição, uma vez que o modelo redistributivo é essencialmente estático. Como foi proposto por Bergh (2005), a política redistributiva afeta também a renda pré-tributação no futuro e não apenas a pós-tributação no presente.

Recentemente, a própria indisposição tradicional do eleitorado estadunidense às políticas relacionadas ao Estado de Bem-estar Social começou a ser dissipada com o incremento constante da desigualdade econômica no país ao longo das últimas três décadas. Com o aumento da distância entre a renda média e a renda do eleitor mediano, nos conceitos do modelo de Meltzer e Richard, o problema da desigualdade econômica deixou de ser circunscrito a certos grupos minoritários hostilizados socialmente e passou a ser temática central no debate político nacional. Esse fenômeno é exemplificado no discurso do Presidente Barack Obama ao Congresso americano em janeiro de 2014, no qual o tema da desigualdade foi o foco central da mensagem (BAKER, 2014) ${ }^{32}$.

\footnotetext{
reduziu-se, coincidindo com o crescimento da percepção de que rendimentos elevados eram oriundos de corrupção e outros processos injustos (GROSFELD; SENIK, 2010).

32 Em 2012, pela primeira vez uma espécie de proteção universal pública no campo da saúde foi aprovada, indicando que o tema da desigualdade social começou a ganhar fôlego em decorrência do agravamento da crise econômica e também do aumento da celeridade do crescimento da desigualdade. Outro
} 
Além de a competição eleitoral ser aberta a diferentes clivagens, a própria economia política da redistribuição dos recursos dentro de uma dada sociedade é multidimensional. Isto porque a decisão do esforço de redistribuição de renda ativa múltiplas clivagens sociais que são distintas da mera diferenciação de rendimentos entre as classes baixas, medianas e altas. Por exemplo, a política redistributiva pode incluir argumentos em defesa ou contrários ao aumento das despesas que sejam motivadas por questões raciais, de gênero, renda ou relações de centro e periferia. E conforme demonstrado por Roemer (1998) o sucesso da temática redistributiva está associado com a sua ortogonalidade em relação a outras clivagens que dividem o eleitorado.

Alesina, Bair e Easterly (2000) mostraram, inclusive, que dentro dos Estados Unidos a demanda por redistribuição em cada cidade é afetada pela extensão da fragmentação etnolinguística da população. Retornando a Gilens (2009), o autor mostra em seu argumento que parte da população estadunidense considerava - durante os anos 1990 - que o segmento social receptor de benefícios da política social era composto majoritariamente por aqueles que não assumiam a responsabilidade pelo próprio aperfeiçoamento pessoal e que não deveriam se fiar no apoio governamental. Sublinhavam ainda que as políticas de proteção social colocavam um peso desnecessário nas costas da classe média pagadora de impostos.

De maneira geral, os estadunidenses não defendiam a ampliação de políticas de bem-estar social, pois acham que

elemento que indica a crescente importância da temática da desigualdade no debate político estadunidense é o papel ocupado pelo movimento Occupy Wall Street e seu slogan: We are the 99\% (PIKETTY, 2014). 
esses programas apoiariam os pobres indignos do apoio do estado. E a percepção a respeito de quem seriam os pobres indignos possuía dois componentes básicos: a maior parte dos receptores dos benefícios seriam os negros e a opinião pública tem a percepção de que os negros são menos comprometidos com a ética do trabalho do que os outros estadunidenses. Existia, portanto, uma percepção generalizada de que o bem-estar tornou-se uma palavra código para raça. Gillens conclui que a oposição à ampliação das políticas redistributivas estava mais associada ao problema racial do que a própria antipatia do eleitorado à redistribuição.

Em outro corte teórico, Thomas Frank (2007) analisa essa questão da multidimensionalidade da política democrática ao discutir como a dimensão dos valores sociais no interior dos Estados Unidos (debate que perpassa questões como a permissão do aborto e do casamento homoafetivo e políticas migratórias) se sobrepõe aos interesses econômicos do eleitor médio. Segundo o argumento do autor, o conservadorismo na dimensão dos valores sociais é proeminente ao passo que a dimensão econômica é deixada de lado. Assim, o interior dos Estados Unidos se mantém fortemente republicano, mesmo que as políticas econômicas defendidas pelo Partido Republicano tenham prejudicado o eleitor decisivo dessa região.

Robinson (2009) discute esse ponto e o apresenta como um dos principais problemas dos modelos redistributivos baseados no teorema do eleitor mediano. Para o autor, a inclusão de novas dimensões do debate político permite o surgimento de clivagens transversais que reduzem a demanda por redistribuição por parte da cidadania. Assim, dada a multidimensionalidade da competição política, as previsões do modelo redistributivo do eleitor mediano tornam-se nebulosas. Isto 
porque os cidadãos possuem diferentes interesses em jogos na definição de qual deve ser a política pública a ser adotada, produzindo uma gama variada de preferências sobre essa temática, inclusive em alguns momentos defendendo posições políticas sobre assuntos que tem como consequência reduzir o seu próprio rendimento econômico final (BARTELS, 2008).

Beramendi e Anderson (2008) resumem esta questão:

Nossa habilidade para entender os aspectos intrincados das políticas distributivas aumentam uma vez que mais dimensões são incorporadas no modelo. Exemplos disso incluem o enigma de porque os pobres não expropriam os ricos em regimes democráticos (ROEMER, 1999; 2009), o papel da renda, aversão ao risco e habilidades específicas dos cidadãos alterando suas preferências pela redistribuição da renda do trabalho (IVERSEN; SOSKICE, 2001; MOENE; WALLERSTEIN, 2001) e dos empregadores (SWENSON, 2002; MARES, 2003); e a interação entre raça e as preferências por redistribuição de diferentes grupos de renda (AUSTEN-SMITH; WALLERSTEIN, 2003; ALESINA; GLAESER, 2004). (BERAMENDI; ANDERSON, 2008, p. 10).

Partindo de percepção semelhante a respeito do problema da multidimensionalidade da disputa política democrática, Roemer (1998) propõe um modelo bidimensional entre dois partidos no qual a competição política acontece entre as dimensões redistributiva e outra qualquer, podendo ser esta conflagrada pelo tema da escravidão, integração, religião, nacionalismo ou mesmo a disputa por valores morais ${ }^{33}$.

\footnotetext{
${ }^{33}$ Laver e Hunt (1992) apresentam evidências de que a política é multidimensional em um conjunto de 20 países. Kitschelt (1994) discute o fato de que nos últimos 30 anos na Europa a política pode ser compreendida como sendo bidimensional. De um lado um eixo redistributivo e do outro um eixo de valores
} 
Ao tentar resolver o modelo n-dimensional, Roemer demonstra claramente a inexistência de um único equilíbrio na linha do modelo redistributivo de Meltzer e Richards. Ademais, além do próprio problema da dimensionalidade da disputa política, Roemer (1998) lista outras possíveis hipóteses encontradas em sua revisão da literatura que explicariam a não aplicação dos modelos redistributivos na realidade histórica contemporânea:

a) eleitores reconhecem a dinâmica adversa decorrente dos efeitos de expropriar os ricos, que possuem talentos produtivos escassos e que deixariam de ser ofertados mediante uma política tributária muito ofensiva, o que reduziria o output total da economia ${ }^{34}$;

b) muitos eleitores cuja renda é menor que mediana tem a expectativa de que vão enriquecer e, portanto, defendem o seu futuro bem-estar;

c) os ricos possuem instrumentos de convencimento do resto da cidadania, disseminados por meio da mídia controlada pelas elites econômicas, de que a redistribuição não seria boa para a comunidade política como um todo; e finalmente

entre posições mais autoritárias e posições mais libertárias, sendo que ambas dimensões tendem a ter uma relação ortogonal entre si. Por sua vez, Kalyvas (1996) e Przeworski e Sprague (1986) argumentam que entre 1880 e 1940 a política europeia teve como dimensões fundamentais a dimensão redistributiva e a dimensão religiosa.

34 Przeworski e Wallerstein (1988) desenvolvem este problema como o poder estrutural do capital em democracias capitalistas. Existe um limite às políticas redistributivas que é não ameaçar o papel da decisão privada e descentralizada do capital sobre a taxa de investimento, o que tem consequências de médio prazo sobre o desempenho econômico afetando, assim, a sustentação política do governo de plantão. 
d) os cidadãos acreditam que as pessoas ricas - e de fato todos - merecem a riqueza que possuem, e, portanto, as taxas de imposto muito elevadas seriam antiéticas.

Inclusive do ponto de vista formal, a partir da inclusão de múltiplas dimensões nos conflitos políticos eleitorais, teoristas sociais como Kenneth Arrow demonstram que regras eleitorais não ditatoriais produzem preferências coletivas irracionais, refutando, entre outras coisas, o próprio requisito da transitividade das preferências sociais coletivas. O equilíbrio do teorema do eleitor mediano supõe como hipótese que a política ocorre estritamente em uma única dimensão. Se as preferências dos cidadãos não forem unidimensionais, a regra não ditatorial não leva a nenhum equilíbrio específico, indicando claramente a irrazoabilidade das preferências coletivas na presença de múltiplas clivagens eleitorais e das próprias conclusões do modelo redistributivo (ARROW, 1963; SEN, 1970).

Por outro lado, ainda que a política não ocorra em uma única dimensão e a questão da redistribuição não possa ser considerada sempre importante, o debate democrático não é caótico, pois além das potenciais demandas gestadas no seio da cidadania, é preciso observar o lado da oferta e, logo, como os partidos enquadram em plataformas e políticas públicas as dimensões latentes da cidadania. Não há incentivo para que os partidos concorram tendo argumentos políticos elaborados para um número vasto de dimensões e clivagens sociais.

A introdução de uma gama variada de temas tende a criar dificuldades para os eleitores no processo de identificação de qual é a orientação do partido nas dimensões que lhe são mais relevantes, impondo também um custo desnecessário aos partidos derivado da necessidade de se posicionar na 
discussão sobre temas que não sejam de interesse de vasto número de eleitores. Em outras palavras, os custos de fomento do debate e difusão de imagens e ideias sobre muitas clivagens podem ser maiores que os benefícios do potencial de conquista de eleitorado. Os partidos tendem, portanto, a eleger alguns temas que sejam eleitoralmente mais lucrativos dentre o conjunto de potencias dimensões que existem num dado contexto socioeconômico ${ }^{35}$.

Posto isto, para se analisar a relação entre democracia e desigualdade é necessário levarmos em conta tanto o lado da demanda quanto o da oferta de redistribuição. Do lado da demanda é necessário analisar qual é o contexto socioeconômico no qual uma parcela majoritária da cidadania apoia a adoção de medidas redistributivas. E do lado da oferta, quando o cálculo do custo benefício da ação política sobre determinada clivagem eleitoral é favorável. Isto é, qual é cenário socioeconômico nos quais os temas redistributivos podem trazem mais votos para os partidos políticos.

É necessária uma teoria sobre qual o contexto no qual a política redistributiva está entre aquelas que são as mais demandadas pela maior parte do eleitorado e ao mesmo tempo são menos custosas para os partidos e, assim, podem ser

\footnotetext{
${ }^{35}$ Ademais, a própria institucionalidade do Estado moderno contemporâneo estimula que a atenção seja voltada em determinados momentos para certos assuntos em detrimento de outros problemas e conflitos sociais. Para Breunig (2011) devido a limitações cognitivas, os próprios decisores realizam uma busca ordenada entre um conjunto limitado de alternativas e avaliam sequencialmente um número finito de alternativas até que possam encontrar uma solução suficientemente boa para o problema percebido. E assim, no agregado, o modelo de decisão sugere que a maioria das mudanças é marginal e em apenas determinados momentos acontecem mudanças radicais em temas que tomam grande proeminência na ordem política do dia.
} 
utilizados pela propaganda política e foco de políticas públicas que aumentem a probabilidade de manutenção do partido incumbente nas posições centrais de governo.

Propomos que o tema da desigualdade econômica só será demandado pela cidadania de maneira mais substantiva nos ambientes eleitorais nos quais uma considerável parcela dos eleitores for de fato sensível a essa temática. E isso ocorrerá somente quando a distância entre pobres e ricos for tão extensa que a questão da desigualdade econômica torna-se passível de ser traduzida em termos de injustiça e desequilíbrio social e não como consequência natural de outros elementos positivamente valorizados pelos cidadãos ${ }^{36}$. Ou seja, quando a distribuição de renda em uma dada sociedade for alvo passível de abjeção social, existindo espaço (verídico ou não) para a denúncia do uso das instituições políticas e econômicas para o benefício de certos grupos específicos em detrimento do todo social. E é plausível assumir que quanto maior for essa distância entre pobres e ricos - isto é quanto maior for a própria desigualdade econômica; maior será o potencial eleitoral da demanda por redistribuição pela cidadania, que passa a enxerga as diferenças entre pobres e ricos sob uma lente política e não apenas econômica.

Em complementação à demanda por redistribuição, a oferta também é afetada de acordo com o aumento do grau de desigualdade econômica de uma dada sociedade. $\mathrm{O}$ resultado líquido do cálculo de custos e benefícios eleitorais varia positivamente com a expansão do fosso social que separa os ricos

\footnotetext{
${ }^{36}$ Como, por exemplo, a competição via mercado em contextos políticos nos quais os cidadãos tendem a valorizar os pontos positivos das relações mercantis centradas na livre iniciativa e no retorno monetário de acordo com a produtividade individual.
} 
dos mais pobres. $\mathrm{O}$ suposto subjacente a esta relação decorre do fato de quanto maior for a desigualdade econômica dentro de uma dada sociedade e mais justa e livres forem as eleições, menores serão os custos que os partidos políticos enfrentam na obtenção do apoio político e também dos votos das classes menos favorecidas na distribuição de renda. Isto porque a falta de recursos desse grupo social torna necessário um menor investimento para obter o apoio político de um indivíduo desfavorecido do que o voto de alguém que pertença às classes médias e altas.

Em sociedades democráticas e desiguais, a quantidade de recursos necessários para obter o apoio das classes mais pobres é menor que os custos de atração das classes médias e altas, o que torna a primeira estratégia mais interessante dado constrangimentos naturais existente nos orçamentos partidários e governamentais. Assim os partidos políticos que ativarem o tema da desigualdade em termos de injustiça e desequilíbrio social competirão para obter os votos da base da sociedade e criarão políticas que reduzam a pobreza deste segmento, o que terá como consequência um efeito negativo substantivo no nível de desigualdade econômica.

Uma ilustração desse argumento é obtida ao se analisar os impactos positivos do Programa Bolsa Família (PBF) no cenário eleitoral brasileiro. Enquanto os benefícios são bastante reduzidos se olharmos os efeitos potenciais de aumento de renda que trariam para famílias de classe média e classe alta no Brasil, o programa foi extremamente importante na superação da pobreza familiar em redutos de miséria no Brasil. Desta forma, os grupos sociais atendidos pelo programa corresponderam eleitoralmente votando maciçamente a favor 
dos incumbentes nas eleições de 2006 e $2010^{37}$. Os valores em 2010, ano da eleição da candidata governista Dilma Rousseff, do PBF variavam entre $R \$ 70,00$ a $R \$ 230,00$ e focavam, sobretudo, as famílias com renda inferior à $\mathrm{R} \$ 140,00$ per capi$\mathrm{ta}^{38}$, o que obviamente definem valores que não trariam tantos dividendos eleitorais se fossem transferidos para famílias de classe média ou alta, que no Brasil possuem renda familiar superior à $\mathrm{R} \$ 7.475,00$, perfazendo $15 \%$ da população brasileira ou mesmo à classe média emergente (classe $\mathrm{C}$ ), que constitui $60 \%$ da população brasileira e cuja renda familiar é superior à R\$ 1734,00 (Neri, 2012) ${ }^{39}$.

Diante destas ponderações, é necessário dar uma nova interpretação às implicações teóricas obtidas a partir do teorema do eleitor mediano, quando aplicado à questão da redistribuição. Diferentemente das conclusões de Downs e Hotelling de que a política majoritária é determinada pela posição do eleitor mediano, esse teorema delimita de fato o máximo potencial da força dos mais pobres dentro de uma determinada sociedade democrática. Isto porque, dada a sua pior posição na escala de renda, estes grupos possuem menos recursos econômicos per capita para serem transferidos para o campo da política. Assim, a única forma de conseguirem atingir e modificar o status quo do sistema político de fato é por meio da atuação coletiva e coordenada. E o máximo de coordenação é obtido quando todos os indivíduos abaixo da renda mediana

37 Uma literatura relativamente desenvolvida já captou efeitos relevantes e positivos do PBF no sucesso eleitoral de Lula em 2006 (HUNTER; POWER, 2007), (NICOLAU; PEIXOTO, 2007), (ZUCCO, 2008), (LICIO; RENNÓ; CASTRO, 2009) e (CORRÊA, 2010).

38 Ministério do Desenvolvimento Social

39 Estimativas populacionais para 2014. Em 2003 a Classe A e B perfaziam apenas 7,6\% da população. A Classe C $37.5 \%$ e as Classes D e E 55\% (Neri, 2012). 
votam conjuntamente para pressionar os líderes democráticos em prol de determinada pauta eleitoral.

Contudo a metade mais pobre da distribuição de renda sempre é suscetível a outras divisões decorrentes da existência de outras clivagens - étnicas, raciais ou de valores - que sejam temas importantes do debate político e que reduzam a capacidade de ação conjunta dos mais pobres como um segmento coeso e defensor da redução das disparidades econômicas.

Ademais, há vasta literatura que apresenta o papel de empreendedores políticos para a ativação de certas clivagens que rompem a unidade das populações menos favorecidas. O exemplo acima citado do estudo de Thomas Frank (2007) em sua leitura sobre a disputa eleitoral no interior dos Estados Unidos é um claro exemplo disso. Outro estudo que mostra a importância do papel do empreendedor político na ativação de clivagens sociais é o estudo de Posner (2004) no qual são discutidas as circunstâncias nas quais as divisões culturais e identitárias tornam-se salientes ${ }^{40}$.

\section{$\mathscr{8}$}

Dada essas ponderações é necessário rever alguns dos achados empíricos apresentados nas seções anteriores e dos

\footnotetext{
${ }^{40}$ Outra forma de entender as clivagens transversais que rompem a solidariedade política entre os mais pobres além do diagnóstico de Frank (2007) é o conceito de falsa consciência política adotado de longa data por teoristas políticos marxistas. No que se refere ao debate sobre o papel das clivagens identitárias, Posner (2004) usando um desenho de pesquisa quase-experimental defende a hipótese de que a saliência política das clivagens culturais não depende da própria clivagem em si, mas sim do tamanho dos grupos e se esses grupos serão uteis na competição política. Isto é, além da potencialidade divisória da dimensão identitária, é necessário que algum empreendedor político desempenhe o papel de ativador do tema no debate político-eleitoral.
} 
próprios mecanismos teóricos sublinhados. Em toda esta literatura que discute a relação entre democracia e desigualdade econômica foi feita uma suposição, ainda não testada, de que os efeitos da democracia sobre a desigualdade econômica seriam homogêneos ao longo de diferentes contextos de desigualdade. Independente, portanto, do contexto socioeconômico no qual a competição democrática ocorre. A dimensão da desigualdade econômica sempre ocuparia o mesmo espaço político eleitoral, não havendo diferenças dos efeitos da democracia em termos de redução da desigualdade e ampliação da redistribuição em sociedades mais igualitárias ou mais desiguais.

A suposição de que a competição política democrática, no que toca aos problemas da desigualdade, ocorreria segundo padrões semelhantes ao longo de todo o contínuo de desigualdade social não parece ser crível quando levantamos o problema da multidimensionalidade da política democrática. E é exatamente sobre esta questão que nos debruçamos nessa pesquisa. Pretendemos verificar se este pressuposto é verdadeiro e para tanto analisamos a hipótese alternativa de que esses efeitos variam ao longo da distribuição de desigualdade econômica devido aos dois mecanismos complementares discutidos acima: a existência ou não da demanda por redistribuição no seio da cidadania e o cálculo eleitoral feito pelas elites políticas partidárias.

Contrário ao consenso da literatura, temos a expectativa que os efeitos da competição democrática sobre o tema da redistribuição em sociedades iguais não deve diferenciá-la de regimes não democráticos, uma vez que a desigualdade não é um tema a ser ativado pela disputa política. Nestes contextos socioeconômicos inexiste a demanda por redistribuição no 
seio da população e os partidos políticos, por sua vez, não têm interesse em ativá-la, buscando obter apoio eleitoral por meio do uso de outras demandas políticas ao acionar outras dimensões ou clivagens sociais.

Por outro lado, em sociedades excessivamente desiguais os partidos políticos tendem a moldar o discurso eleitoral e as próprias políticas públicas em busca da minimização dos efeitos da desigualdade econômica, uma vez que a intensidade da demanda por redistribuição por parte da cidadania torna-se um vetor que diminui a importância de outras clivagens latentes. E os partidos políticos teriam uma maior tendência a atender a esta demanda e tratar do problema da desigualdade econômica como uma questão que excede os limites da economia de mercado, refletindo, outrossim, conceitos de injustiça e exploração social e de denúncia do uso das instituições políticas e econômicas para benefício de certos grupos privilegiados.

Assim, ao colocarmos em questionamento o pressuposto da homogeneidade dos efeitos da democracia, tentamos responder à seguinte indagação: seriam os efeitos equalizadores de um regime político democrático em uma sociedade desigual semelhantes aos efeitos equalizadores de um regime político democrático em uma sociedade igualitária?

Sublinhamos mais uma vez o significado que damos para o termo democracia, definido nessa pesquisa como um processo competitivo de escolha de lideranças políticas. A diferenciação de padrões recorrentes em regimes democráticos em relação a não democracia decorre, portanto, de implicações que a competição política tem para a temática em análise. Em sociedades relativamente iguais, o tema da desigualdade econômica não está entre os principais temas da agenda política da competição eleitoral. Já em sociedades relativamente 
desiguais, as chances de que um dos partidos que disputam as eleições democráticas invista na temática da necessidade de redução da desigualdade, traduzindo-a em termos de injustiça e desequilíbrio, e, portanto, defendendo o imperativo moral de que é necessário reduzi-la, é maior. Posto isso, iremos verificar se os efeitos da democracia sobre a desigualdade econômica são condicionados às situações nas quais o tema da desigualdade pode ser ativado de maneira crível por algum dos competidores políticos.

Como foi apontado pela literatura que discute os efeitos da desigualdade econômica nos processos de democratização, uma das dificuldades de se criar uma democracia em sociedades desiguais é o temor das elites políticas e econômicas decorrente da ameaça de redistribuição que são levados em conta em seu cálculo estratégico sobre os custos de repressão e os custos de tolerância à transferência de poder às classes mais desfavorecidas (BOIX, 2003; ACEMOGLU; ROBINSON, 2006; HOULE, 2009). Desta feita, quando uma transição democrática em um país relativamente desigual é bem-sucedida, é provável que esta democracia desigual esteja associada a um processo mais efetivo de redistribuição de riqueza do que o padrão encontrado em sociedades democráticas igualitárias.

As diferenças entre os temas prioritários das agendas pós-redemocratização na América Latina e no Leste Europeu deixam indícios de que é importante diferenciar os efeitos da democracia ao longo deste contínuo da desigualdade econômica. As democracias recém-saídas da esfera de influência do sistema político soviético são bastante claras a respeito do funcionamento deste padrão de ação sobre a desigualdade. Como os regimes autoritários a partir dos quais estas democracias emergiam foram regimes que produziram níveis altos de igualdade econômica (os mais altos encontrados até agora), o tema da desigualdade não estava no topo da lista de prioridades 
dos primeiros competidores políticos. Por outro lado, após a redemocratização latino-americana, que emergia de regimes autoritários que produziram níveis recordes de desigualdade econômica, como o caso brasileiro, o tema do resgate da dívida social tornou-se uma das principais bandeiras políticas, disputando espaço na agenda apenas com os debates sobre a inflação e sobre o próprio processo de redemocratização ${ }^{41}$.

Para responder a esta questão de pesquisa iremos analisar as duas hipóteses abaixo que nos permitem explorar (a) se na média as democracias reduzem a desigualdade econômica em relação às ditaduras (H1: hipótese tradicional da homogeneidade dos efeitos) e (b) se os efeitos dos regimes políticos democráticos sobre a desigualdade econômica são crescentes ao longo da distribuição de desigualdade, sendo mais acentuados nas sociedades mais desiguais (H2: hipótese da heterogeneidade dos efeitos).

H1: As democracias possuem em média um efeito negativo sobre a desigualdade.

H2: Os efeitos negativos da democracia sobre a desigualdade são maiores nas sociedades mais desiguais e tendem a ser menos relevantes em sociedades mais iguais.

${ }^{41}$ O artigo de Lupu e Pontusson (2011) analisa essa questão segundo um prisma distinto, mas que converge com o argumento teórico proposto nesta pesquisa. Para ambos autores, o que afeta a economia política da redistribuição de renda é a estrutura da desigualdade. Para justificar o argumento, os autores propõem um modelo no qual o posicionamento estrutural da classe média em relação aos pobres e os ricos determina o apoio à redistribuição: "na ausência de clivagens étnicas transversais, os eleitores com renda intermediária terão empatia com os pobres e apoiaram políticas redistributivas quando a distância entre a renda média e dos pobres é pequena em relação à distância de renda entre a renda média e a renda dos mais ricos" (LUPU; PONTUSSON, 2011, p. 316). 


\subsection{Metodologia}

Na seção anterior desenvolvemos a nossa proposta teórica e hipóteses de pesquisa. Nesta apresentamos o método que nos permitirá testar a hipótese da heterogeneidade dos efeitos da democracia sobre a desigualdade e como agiremos para superar a questão da endogenia presente na relação entre democracia e desigualdade econômica. Isto porque como já apresentado no Capítulo 1, existe uma vasta literatura que discute os potenciais efeitos negativos que a desigualdade pode trazer aos processos de democratização. A questão da presença de endogeneidade na relação entre democracia e desigualdade é fundamental, pois vasto conjunto de estudos discute a hipótese de que a desigualdade é negativamente relacionada com a probabilidade de um dado país tornar-se e/ou permanecer sendo uma democracia.

Na próxima subseção apresentamos a estratégia adotada para identificar o efeito da democracia sobre a desigualdade, controlando o problema da causalidade reversa. $\mathrm{O}$ método que utilizamos e justificamos abaixo é o de variáveis instrumentais. Na subseção seguinte introduzimos o método de regressão quantílica, adequado para a estimação dos efeitos heterogêneos da democracia sobre a desigualdade.

Para a identificação dos países que são democráticos, utilizamos a base sobre regimes políticos de Cheibub, Gandhi e Vreeland (2010). Assumimos a mensuração dicotômica defendida pelos autores que definem democracia como um regime político no qual existe competição política por meio de eleições ${ }^{42}$. De maneira simplificada podemos dizer que

\footnotetext{
${ }^{42}$ Cheibub, Gandhi e Vreeland (2010) atualizam a base de Przeworski, Alvarez, Cheibub e Limongi (2000).
} 
consideramos como democrático todos os regimes políticos nos quais o partido incumbente deixa o poder por meio de eleições livres e justas. E para mensurar a desigualdade econômica utilizamos o conjunto de dados produzido pelo Projeto Desigualdade da Universidade do Texas (University of Texas Inequality Project - UTIP), que utiliza métodos baseados no componente entre grupos do Índice $\mathrm{T}$ de Theil. $\mathrm{O}$ banco de dados inclui 3686 pontos de dados de EHII para 145 países $^{43}$. A unidade básica de análise é um país/ano e o banco tem o formato de um painel desbalanceado de 1963 à 2008. Apresentamos uma discussão mais aprofundada sobre as definições teóricas e metodológicas de democracia e desigualdade econômica no Capítulo 3.

\subsection{Endogenia nas relações entre democracia e desigualdade econômica}

Na relação descritiva entre democracia e desigualdade ${ }^{44}$, verificamos que a democracia está associada a níveis menores de desigualdade. Contudo apenas esta informação descritiva não nos permite compreender qual é o processo causal presente nessa relação. Como existe na literatura e no próprio mundo da política a percepção de que a democratização estimularia a adoção de uma maior redistribuição de renda das elites para as classes menos favorecidas, a transição democrática é custosa para às elites econômicas. E como consequência é

${ }^{43} \mathrm{O}$ banco final possui projeções lineares para reduzir o problema de dados faltantes de desigualdade econômica para intervalos de até 8 anos. O banco de dados foi ampliado para 4138 anos - países. A interpolação não é problemática dado que a variação na desigualdade é sempre bastante lenta e gradual. Ademais, os resultados são idênticos quando usamos o banco original.

${ }^{44}$ Apresentada no capítulo 3. 
possível que exista uma resistência por parte destas elites contra avanços democráticos justamente nas sociedades que possuem uma distribuição de renda mais desigual (BOIX, 2003; ACEMOGLU; ROBINSON, 2006; HOULE, 2009) ${ }^{45}$. Caso tal processo realmente exista, os sistemas políticos democráticos tenderiam a ser uma seleção predileta de sociedades mais igualitárias e, desse modo, a mera associação entre democracia e desigualdade não confirmaria a hipótese de que a democracia é um regime político capaz de reduzir as desigualdades econômicas entre os indivíduos.

Para resolver o problema da endogeneidade presente na relação entre democracia e desigualdade, usaremos a técnica de variável instrumental (IV). A intuição básica subjacente à abordagem de IV é estimar a variável endógena, no nosso caso, a variável de democracia (a independente com problema de causalidade reversa), usando uma variável exógena e que seja correlacionada com a variável endógena, mas que não esteja correlacionada de nenhuma outra forma com a variável dependente, em nosso caso, a desigualdade econômica. Desta forma, quaisquer efeitos da variável instrumental sobre a variável dependente seriam canalizados única e exclusivamente por meio da variável endógena (ANGRIST; KRUEGER, 2001; ANGRIST; PISCHKE, 2008) ${ }^{46}$. Isto é, devemos encontrar uma variável que não seja relacionada com o nível de desigualdade

\footnotetext{
45 Boix (2003) demonstrou que altos níveis de desigualdade podem prejudicar a democratização e a consolidação das democracias. Houle (2009) e Acemoglu e Robinson (2006) também investigaram a probabilidade de que alta desigualdade prejudique a consolidação da democracia devido às expectativas de redistribuição que existe em sociedades democráticas.

46 A Hipótese de Restrição de Exclusão assume que a variável instrumental é não correlacionada com qualquer outra variável não observada que esteja correlacionada com a variável dependente.
} 
econômica encontrada no país e nem com qualquer outro fator determinante da desigualdade com exceção apenas da variável endógena em questão: $\mathrm{o}$ indicador de democracia ${ }^{47}$.

A validade da estimação por variável instrumental depende crucialmente da seleção de um instrumento adequado que satisfaça dois critérios: (a) ser correlacionado com a variável endógena; e (b) não possuir um efeito causal na variável dependente (ou, por extensão, no termo de erro da equação estimada). Estes critérios implicam que qualquer alteração na variável dependente que seja resultado de mudanças nos valores de um instrumento deve ser atribuída ao canal causal proporcionado pela variável endógena e, deste modo, livre da relação que existe entre a variável dependente e a variável endógena (SAVUN; TIRONE, 2011).

Nesta pesquisa selecionamos alguns potenciais instrumentos de democracia usados na literatura comparada e também propomos outras variáveis instrumentais. A partir desta seleção, analisamos e testamos quais são aqueles instrumentos que atendem aos dois critérios. Para a seleção destes potenciais instrumentos utilizamos duas abordagens distintas: a) variáveis utilizadas na literatura sobre democratização e que não são consideradas potenciais fatores causais da desigualdade; b) variáveis completamente exógenas aos processos de democratização e desigualdade econômica, mas que estão empiricamente relacionados com democracia.

Desta seleção, apresentamos três diferentes conjuntos de instrumentos para estimar o verdadeiro efeito da democracia na desigualdade. O primeiro é composto de um conjunto de

\footnotetext{
${ }^{47}$ Para uma apresentação mais pormenorizada do método de variável instrumental vide apêndice $A$.
} 
variáveis relacionadas aos processos de difusão de democracia, tendo em vista a vasta literatura que discute os efeitos que o aumento do número de democracias no mundo tem sobre a permanência de regimes políticos autoritários e democráticos. E por outro lado, até onde sabemos, não existem trabalhos que apontem uma relação entre os efeitos da difusão de democracia pelo mundo e a desigualdade econômica dentro de um determinado país. Contudo, este conjunto de instrumentos não possui uma natureza completamente exógena ao mundo da política. O mesmo acontece com o segundo instrumento, herança colonial britânica.

O terceiro conjunto é composto por variáveis que captam o posicionamento longitudinal de um país no planisfério. As duas variáveis utilizadas para captar esse fenômeno são por definição estritamente exógena à relação entre democracia e desigualdade, uma vez que o posicionamento longitudinal de um país é um dado independente de sua conformação política e social e também não existem estudos ou teorias, até onde pudemos verificar, que relacionem o posicionamento longitudinal de um país com a sua desigualdade econômica.

No Quadro 1 listamos os potenciais instrumentos de democracia que foram selecionados para analisar o impacto desta sobre a desigualdade econômica. Da lista dos instrumentos que mensura o fenômeno da difusão de democracia, os três primeiros são instrumentos que diferem pelo âmbito geográfico, respectivamente no mundo, no continente e no subcontinente, e os dois seguintes são medida resumo das três variáveis anteriores. Já a variável herança britânica é um indicador da existência ou não de alguma herança colonial britânica no país, incluindo o próprio Reino Unido. Além das colônias britânicas, são considerados como parte deste conjunto os 
países que foram colonizados pelas ex-colônias britânicas EUA e Austrália.

Quadro 1 - Instrumentos de democracia

\section{1) Instrumentos de Difusão:}

a) Difusão mundial de democracia: número de democracia existentes no ano / número de países existentes no ano. [difmundo]

b) Difusão continental de democracia: número de democracia existentes no continente no ano/número de países existentes no continente no ano. [difcont]

c) Difusão subcontinental de democracia: número de democracia existentes no subcontinente no ano/número de países existentes no subcontinente no ano. [difregiao]

d) Difusão ponderada de democracia: média simples das medidas (a); (b) e (c) [difpond1]

e) Difusão ponderada de democracia dado a relevância regional e continental do país: média de (a), (b) e (c), ponderada pelo peso territorial do país no continente e no subcontinente, respectivamente [difpond2]

2) Herança Britânica: indica se o país possui herança britânica, incluindo o próprio Reino Unido e ex-colônias americanas e australianas, adaptado de Hadenius e Teorell (2005) [british]

3) Localização Longitudinal:

a) Hemisférico Oriental: indica se o país possui localização longitudinal ao oriente do meridiano $36^{\circ}$ (Turquia). [horiental]

b) Longitude: log da longitude de um país calculado por 105+longitude. [llong]

O terceiro e último conjunto de instrumentos são estritamente exógenos, pois mensuram de diferentes formas o posicionamento longitudinal de um país. Contudo, se espera que a relação com democracia seja mais fraca. Mensuramos a localização longitudinal com um indicador se o país está localizado na fração oriental do planisfério, sendo a linha divisória traçada no meridiano $36^{\circ}$ Leste, que divide o 
continente europeu do continente asiático ${ }^{48}$. O segundo é a própria transformação logarítmica da longitude do país. Optamos pela transformação logarítmica de forma a reduzir a influência de alguns poucos casos específicos do continente da Oceania que possuem valores absolutos longitudinais muito superiores ao restante da amostra ${ }^{49}$.

\subsubsection{Difusão democrática como instrumento de democracia}

No primeiro conjunto de instrumentos estão as medidas da difusão de democracia. Como uma importante literatura sobre as transições políticas mostrou, um dos importantes componentes do processo de democratização é a atmosfera política internacional (WEJNERT, 2005; BRINKS E COPPEDGE, 2006; GLEDITSCH; WARD, 2006; MAINWARING; PÉREZ LIÑÁN, 2009). Todos estes autores defendem a ideia de que existe algum mecanismo de difusão ou contágio por meio do qual os regimes democráticos são propagados. Isto porque os processos de democratização e transições autoritárias se agrupam no tempo e no espaço, sugerindo a ocorrência de uma difusão e da existência de dependências transfronteiriças que influenciam o desenvolvimento e persistência das instituições políticas (NOGUEIRA, 2011).

\footnotetext{
${ }^{48} \mathrm{O}$ meridiano 36L atravessa a Rússia europeia, a Ucrânia, o interior da Turquia, o Oriente Médio, passando pela Síria, Jordânia e Arábia Saudita e no continente Africano atravessa o Chifre da África cortando o Sudão, Etiópia e Quênia e ao sul atravessa Tanzânia e Moçambique. Destes países a Turquia, Ucrânia, Sudão, Tanzânia e Moçambique estão no hemisfério ocidental. Os outros são considerados como localizado na esfera oriental.

49 A Oceania é o único continente que possui longitude superior a 138, sendo que a variação longitudinal nesse continente é entre 133 a 179.15 .
} 
Bunce e Wolchik (2006) definem difusão como um processo no qual ideias, instituições, modelos de políticas públicas, ou repertórios de comportamento se propagam de um centro geográfico para outras regiões. Mas o processo de difusão não requer apenas a existência de desdobramentos similares, pois exige também o reconhecimento de um novo elemento em um determinado país A por atores externos em $\mathrm{B}$ e um compromisso por indivíduos e grupos de B para emulá-lo em sua própria localidade.

Além da associação positiva com democracia, para que o instrumento cumpra com sua função metodológica, é necessário, portanto, que seja verdadeira a hipótese de que a variável difusão de democracia não possui outro canal por meio do qual os seus efeitos sobre a desigualdade sejam transmitidos, além do próprio mecanismo da competição eleitoral em regime democrático.

Do ponto de vista da literatura, podemos frisar que até onde pudemos encontrar informações, não há discussão sobre qualquer influência da difusão de democracia no mundo sobre a desigualdade econômica dentro de cada um dos países. Desta forma, podemos assumir que quaisquer efeitos que sejam estimados por meio da técnica de variável instrumental podem ser atribuídos ao efeito da democracia sobre a desigualdade, purificado dos problemas de causalidade reversa. Além do mais, no capítulo 4 realizamos alguns testes estatísticos que comprovam a adequabilidade do instrumento, aumentando nossa confiança neste pressuposto.

$\mathrm{O}$ argumento subjacente ao efeito democratizante da difusão decorre do suposto de que com o aumento no número de democracias ao redor de um país A, o grupo político que defende a democratização neste país (ou que defende a 
manutenção da democracia) é empoderado. Ideias, modelos e afins podem se espalhar para além das fronteiras, simplesmente por fornecerem precedentes atraentes para os atores em A, influenciando o pensamento, objetivos e comportamento de lideranças (BUNCE; WOLCHIK, 2006). Do outro lado, não existem indícios de um canal de covariação da difusão de democracia no sistema internacional com a desigualdade econômica interna de um dado país que não seja, necessariamente, transmitido pelos próprios efeitos da competição política democrática.

Do ponto de vista prático, iremos mensurar a difusão de democracia em três diferentes proporções: uma proporção em nível regional, outra em nível continental e a terceira em nível global. Para realizar esse cálculo dividimos o mundo em cinco continentes distintos e dez subcontinentes. Os cinco continentes são: 1. África e Oriente Médio; 2. América; 3. Ásia; 4. Europa; e 5. Oceania. E os dez subcontinentes são: 1. Europa Oriental e pós-URSS; 2. Europa Ocidental; 3. Norte da África e Oriente Médio; 4. África Subsaariana; 5. América do Norte e Central; 6. América do Sul; 7. Centro e Extremo Oriente; 8. Sudeste Asiático; 9. Ásia do Sul; e 10. Oceania. Assim, o cálculo para cada uma destas proporções é basicamente o mesmo, variando apenas a circunscrição geográfica:

$$
\operatorname{Dif}_{i t}=\left[\frac{D_{t}}{\mathrm{~N}_{t}}\right]
$$

no qual $D_{t}$ representa o número de democracias no ano $t$ na região, continente ou em todo mundo e $N_{t}$ representa o número total de países neste mesmo ano $t$ na mesma circunscrição 
geográfica, sendo que para ambos os termos da proporção não contabilizamos na contagem de países e democracias o próprio país.

Além das três proporções puras de difusão, também criamos duas medidas resumos de difusão. Na primeira calculamos a média simples das três diferentes proporções da Eq. 2.1 de cada país e na segunda ponderamos as proporções regionais e continentais pelo espaço territorial ocupado pelo país na região e no continente, respectivamente. Abaixo apresentamos as duas fórmulas:

$$
\operatorname{Difpond}_{i t}=\left[\frac{D_{1 t}}{\mathrm{~N}_{1 t}}+\frac{D_{2 t}}{\mathrm{~N}_{2 t}}+\frac{D_{3 t}}{\mathrm{~N}_{3 t}}\right] / 3
$$

i) Difusão Ponderada de Democracia: Onde $D_{1}$ é o número de democracias no mundo no ano $t$ e $\mathrm{N}_{1}$ é o número de países no mundo no mesmo ano $t ; D_{2}$ é o número de democracias no continente do país $i$ no ano $t$ e $\mathrm{N}_{2}$ é o número de países no continente do país $i$ no mesmo ano; $D_{3}$ é o número de democracias no subcontinente do país $i$ no ano $t$ e $\mathrm{N}_{3}$ é o número de países na região (ou subcontinente) do país $i$ no mesmo ano.

$\operatorname{Difpond}_{i t}=\left[\frac{D_{1 t}}{\mathrm{~N}_{1 t}}+\frac{D_{2 t}}{\mathrm{~N}_{2 t}} *\left(1-\frac{\mathrm{A}_{t}}{C_{i}}\right)+\frac{D_{3 t}}{\mathrm{~N}_{3 t}} *\left(1-\frac{\mathrm{A}_{t}}{R_{i}}\right)\right] / 3$

ii) Difusão Ponderada de Democracia dado a relevância regional e continental do país: onde repete-se as medidas do item anterior e acrescentamos: $A_{t}$ - a área territorial do país no ano $t ; \mathrm{C}_{\mathrm{i}}$ - a área do Continente onde o país $i$ 
está localizado e $\mathrm{R}$ - a área da Região onde o país $i$ está localizado. Obviamente a medida de $\mathrm{A}_{\mathrm{t}}$ tende a ser estável na maior parte do tempo, mas em alguns casos excepcionais certos países, como o Paquistão, tiveram seu território reduzido.

Na Tabela 1 apresentamos as correlações entre as cinco variáveis que mensuram a difusão de democracia, mais o próprio indicador de democracia mensurado por Cheibub, Gandhi e Vreeland (2010). Além das duas medidas ponderadas de difusão (Difpond1 e Difpond2), incluímos as três variáveis puras que mensuram a difusão de democracia no mundo (Difmundo), no continente (Difcont) e na região (Difregião). Com exceção das correlações de Difmundo com as outras variáveis, inclusive as próprias variáveis de difusão e de apenas 0.20 com o indicador de democracia, todas as outras correlações são bastante altas ${ }^{50}$.

Constatações interessantes podem ser obtidas a partir desta tabela de correlações. A principal constatação é que difusão mundial de democracia (difmundo) é menos correlacionada com todas as outras variáveis, incluindo o próprio indicador de democracia. Já o instrumento difusão regional de democracia (difregião) possui a maior correlação com democracia e com os dois índices de ponderados difusão, o que aponta para o fato que o processo de difusão tem o seu efeito principal nas regiões e continentes e não sobre todo o globo. E as correlações de difusão continental de democracia (difcont) estão em um ponto intermediário entre as de

\footnotetext{
50 Adiantando resultados apresentados mais a frente, os testes estatísticos do capítulo 4 indicam que a identificação de democracia é realizada com mais acurácia nos modelos nos quais introduzimos as variáveis puras de difusão de democracia ao invés das variáveis ponderadas.
} 
difmundo e difregião. Estes dados indicam que o processo de difusão de democracia é um fenômeno mais sensível regional do que globalmente, o que é um achado esperado uma vez que os processos de mútua interdependência são muito mais comuns entre países que se localizam em regiões próximas do que entre países que possuem uma distância geográfica maior.

Tabela 1 - Correlações entre democracia e difusão de democracia

\begin{tabular}{lccccc}
\hline & Democracia & Difpond $_{1}$ & Difpond $_{2}$ & Difmundo $^{\text {Difcont }}$ \\
\hline Difregiao & 0.61 & 0.95 & 0.93 & 0.33 & 0.86 \\
Difcont & 0.54 & 0.95 & 0.92 & 0.39 & \\
Difmundo & 0.20 & 0.52 & 0.52 & & \\
Difpond $_{2}$ & 0.57 & 0.98 & & & \\
Difpond $_{1}$ & 0.59 & & & & \\
\hline
\end{tabular}

Fonte: Cheibub, Gandhi e Vreeland (2010) - CGV

Finalmente, o instrumento que mensura a herança colonial britânica é retirado da literatura de política comparada. Em Eichengreen e Leblang (2008) a herança colonial britânica é usada como instrumento para estimar os efeitos da democracia sobre a globalização, mensurada como o nível de abertura comercial, num cenário que de acordo com os autores também sofre do problema de causalidade reversa ${ }^{51}$.

Na Tabela 2 apresentamos as correlações entre os outros três instrumentos selecionados e democracia. Podemos

51 Outras variáveis utilizadas como potenciais instrumentos de democracia por Eichengreen e Leblang (2008) foram o número de anos desde a independência do país usadas também por Persson (2005), Mobarak (2005) e Acemoglu, Robinson e Yared (2008); a origem legal do sistema jurídico do país; e a distância média do país das outras democracias do sistema internacional (MOBARAK, 2005; PERSSON; TABELLINI, 2006; ACEMOGLU et al., 2008; EICHENGREEN; LEBLANG, 2008). 
observar que as correlações são menores do que as encontradas com os instrumentos anteriores. E praticamente não existe correlação entre a herança colonial britânica e o indicador de democracia, o que vai na contramão da literatura comparada e é um resultado que se mantém consistente nas análises do capítulo 4. Já as correlações do indicador hemisférico e da longitude são maiores e semelhantes entre si, indicando que estar na parcela ocidental do mundo está empiricamente associado com democracia enquanto o oriente é mais associado a regimes não democráticos. No capítulo 4 apresentamos os testes que avaliam quais destes instrumentos são adequados para identificar a relação da democracia sobre a desigualdade.

Tabela 2 - Correlações entre democracia e os outros instrumentos

\begin{tabular}{lc}
\hline & Democracia \\
\hline British & 0.03 \\
Hemisfério Oriental & -0.20 \\
Longitude & -0.20 \\
\hline
\end{tabular}

Fonte: CGV

Por meio dos testes de Stock, Wright e Yogo (2002) demonstramos no Capítulo 4 que os instrumentos de difusão de democracia e os indicadores longitudinais são os instrumentos mais adequados para identificar democracia, enquanto a herança colonial britânica não está correlacionada com democracia, não atendendo a um dos critérios fundamentais da estimação por variável instrumental - a correlação entre o instrumento e a variável endógena. Por fim, nas principais especificações os instrumentos de difusão e de longitude atendem também aos requisitos exigidos pela hipótese de restrição de exclusão. 


\subsubsection{Estimação dos efeitos heterogêneos da democracia sobre a desigualdade econômica}

Conforme apresentamos na secao 1 deste capítulo pretendemos analisar duas hipóteses rivais sobre os efeitos da democracia na desigualdade econômica. A primeira hipótese, tradicional, busca avaliar se as $\mathbf{H 1}$ - as democracias possuem em média um efeito negativo sobre a desigualdade. Já a segunda hipótese, a hipótese alternativa, busca inserir na discussão a questão da multidimensionalidade do conflito político e as condições e contextos nos quais existem incentivos para que surja no seio da população uma demanda por maior redistribuição e os partidos políticos atendam a esta demanda oferecendo uma plataforma eleitoral e políticas públicas que tenham como objetivo principal a redução da desigualdade econômica: H2 - os efeitos negativos da democracia sobre a desigualdade são maiores nas sociedades mais desiguais e tendem a ser menos relevantes em sociedades mais iguais.

É necessário, portanto, adotar um método de estimação flexível o suficiente para estimar os efeitos heterogêneos da democracia sobre a desigualdade econômica ao longo da própria distribuição da desigualdade, uma vez que queremos testar a hipótese de que os efeitos da democracia sobre a desigualdade são maiores nas democracias mais desiguais. O método mais adequado para responder a esse problema de pesquisa é o arcabouço de Regressão Quantílica desenvolvido por Roger Koenker e Gilbert Bassett (1978).

Sublinhamos mais uma vez que essa questão de pesquisa e a abordagem teórica proposta ainda não foram discutidas em nenhum dos estudos da literatura de econômica política comparada sobre desigualdade econômica. Todas as pesquisas 
anteriores trabalharam com hipóteses que assumem que os efeitos da democracia sobre a desigualdade são homogêneos. E na maior parte das vezes foram utilizados como método de inferência regressões por Mínimos Quadrados Ordinários para dados em Painel. Assim, uma das contribuições mais relevantes desta pesquisa será o exame dos efeitos de um regime político democrático ao longo de todas as diferentes magnitudes de desigualdade econômica.

A Regressão Quantílica introduzida por Koenker e Bassett (1978) é uma extensão direta da estimação clássica das médias condicionais por Mínimos Quadrados Ordinários (MQO) para estimação de modelos por funções condicionadas nos quantis. O método emprega um estimador de mínimos desvios absolutos que pode ser utilizado para estimar os percentis da distribuição condicionada. Deste modo, a Regressão Quantílica possibilita a detecção de relações causais distintas para vários pontos da distribuição de uma variável dependente. Isto porque ela fornece estimativas dos efeitos de cada covariável (variável independente de interesse e controles) ao longo de toda a distribuição condicional da variável dependente ${ }^{52}$. Em contraste, a regressão por MQO tradicional fornece estimativas apenas para a média condicional (BREUNIG, 2011).

Uma propriedade importante do método de Regressão Quantílica é sua robustez à presença de outliers na variável dependente, uma vez que a estimação é feita condicionada à posição do ponto dentro da distribuição da própria variável dependente. Ademais, como os dados estão estruturados em forma longitudinal, pretendemos estimar a relação entre

\footnotetext{
52 Para uma apresentação mais pormenorizada do método de Regressão Quantílica com variável instrumental vide apêndice B.
} 
democracia e desigualdade por meio de Regressão Quantílica com Variável Instrumental para Dados em Painel Empilhados.

O método de estimação por efeitos fixos não é adequado para a análise da relação entre democracia e desigualdade, pois $57.2 \%$ dos pontos de dados são países-anos pertencentes a países cujos regimes políticos não transitaram ao longo do período analisado. Assim o estimador de efeito fixo consideraria a permanência em um regime democrático ou em um regime autoritário durante todo o período como um efeito fixo a ser eliminado junto com a heterogeneidade específica não observada. Visando diminuir a variação dos dados, incluímos na regressão efeitos fixos continentais e em algumas estimações efeitos fixos temporais. Desta forma, eventuais especificidades regionais ou choques exógenos que tenham impactado a desigualdade são retirados na estimação dos efeitos das covariáveis.

No primeiro passo do processo de estimação, utilizamos as variáveis instrumentais para prever os valores defasados de democracia e depois, no segundo passo, estimamos por meio de uma série de regressões quantílicas a relação entre democracia e desigualdade usando o índice de GINI para desigualdade e os valores previstos no primeiro passo de democracia defasada para todos os decis da distribuição de desigualdade econômica.

Visando reduzir a necessidade de impor hipóteses adicionais para a validade das estimativas, as variâncias dos coeficientes da RQ são estimadas pelo método não paramétrico de bootstrapping (EFRON, 1979; EFRON, 1982; CAMERON; TRIVEDI, 2005). O método de bootstrap permite evitar fortes suposições paramétricas sobre a estrutura do termo de erro ou fórmulas complexas para o cálculo dos erros padrões ${ }^{53}$.

\footnotetext{
${ }^{53}$ Foram utilizadas 1000 repetições no procedimento de bootstrapping. Para uma apresentação mais pormenorizada do método de bootstrap vide apêndice C.
} 
No primeiro passo, utilizaremos como variável independente de interesse uma variável de difusão de democracia defasada em dois anos e a variável democracia defasada em um ano. Optamos por defasar a variável independente para minimizar ao máximo a possibilidade de existência de endogenia na relação de interesse. Nossa hipótese foi testada sem variáveis defasadas e os resultados continuam semelhantes. Repetimos estas estimativas em quatro amostras diferentes. A primeira é a nossa amostra completa, a segundo tem como unidade temporal básica um triênio, a terceira quinquênios, a quarta decênios e, por fim, a quinta e última intervalos temporais de 15 anos. O objetivo principal das amostras com maior intervalo temporal é minimizar o problema de dados faltantes, sendo um procedimento recorrentemente utilizado na literatura que debate a relação entre democracia e desigualdade. Em todas as estimações, os resultados são semelhantes.

Desta forma, apresentamos abaixo as regressões estimadas. Os coeficientes de interesse são os diferentes $\boldsymbol{\beta} 2$ estimados para cada decil da distribuição de desigualdade econômica. A variável de democracia está defasada em um ano e os instrumentos, quando variáveis no tempo, estão defasados em dois anos.

\section{1) EQUAÇÃO ESTIMADA NO PRIMEIRO PASSO:}

$\mathrm{L} . D E M O_{\text {it }}=\boldsymbol{\alpha i}+\boldsymbol{\beta} 6$ controles $_{\mathrm{it}}+\boldsymbol{\beta} 7$ L2. Instrumentos $_{\mathrm{it}}+$ $\beta 8$ continentes $+\beta$ 9 tend $+\boldsymbol{\beta} 10$ tend $^{2}+\boldsymbol{\pi}_{\text {it }}$

\section{2) EQUAÇÃO ESTIMADA NO SEGUNDO PASSO:}

Assumindo especificação linear para o $\tau$ - ésimo quantil:

$Q_{\tau}[. \mid X=x]=\alpha i+\beta 1$ controles $_{\text {it }}+\boldsymbol{\beta} 2$ L.DEMO $_{\text {it }}+$

$\beta 3$ continentes $+\boldsymbol{\beta} 4$ tend $+\boldsymbol{\beta} 5$ tend $^{2}+\boldsymbol{\varepsilon}_{\mathrm{it}}$ 
No qual $Q_{\tau}[\cdot \mid \mathbf{X}=\mathrm{x}] \equiv \frac{\operatorname{Inf}}{q} \boldsymbol{P}(. \leq \mathbf{q} \mid \mathbf{X}=\mathrm{x}) \geq \tau$ sendo o $\tau$-ésimo quantil condicionado na distribuição da variável dependente EHII.

Assim concluímos a abordagem teórica e metodológica desta pesquisa. No próximo capítulo apresentaremos as definições de democracia e desigualdade econômica em seus pormenores e os dados descritivos da relação de interesse. Por fim, nos dois últimos capítulos apresentamos os resultados empíricos da análise proposta. 